\title{
Hydrotalcite-wrapped Co-B alloy with enhanced oxygen evolution activity
}

\author{
Xue Leng a, Kuang-Hsu Wu a, Bing-Jian Su c, Ling-Yun Jang c, Ian R. Gentle a, Da-Wei Wang a,b,* \\ a School of Chemistry and Molecular Biosciences, The University of Queensland, Brisbane 4072, Australia \\ b School of Chemical Engineering, University of New South Wales, Sydney, NSW 2052, Australia \\ c Research Division, National Synchrotron Radiation Research Center, Hsinchu 300, Taiwan, China
}

\section{A R T I C L E I N F O}

\section{Article history:}

Received 8 February 2017

Accepted 4 March 2017

Published 5 June 2017

\section{Keywords:}

Amorphous alloy

Oxygen evolution reaction

Electrocatalyst

\begin{abstract}
A B S T R A C T
Water oxidation is one of the most attractive techniques for intermittent renewable energy conversion and storage. The oxygen evolution electrocatalytic performance of an amorphous Co-B alloy and its derivatives were studied. These materials were chemically synthesized by reducing a Co salt with $\mathrm{NaBH}_{4}$. The amorphous Co-B alloy showed good electrocatalytic activity in oxygen evolution but its stability was poor. A hydrotalcite-wrapped Co-B alloy was synthesized by mild oxidation. The electrocatalytic activity of this material in the oxygen evolution reaction was better than that of a commercially available Ir/C catalyst.
\end{abstract}

(C) 2017, Dalian Institute of Chemical Physics, Chinese Academy of Sciences. Published by Elsevier B.V. All rights reserved.

\section{Introduction}

The oxygen evolution reaction (OER) is an important electrocatalytic process in water electrosplitting, metal electrowinning, and metal-air batteries. However, the OER has sluggish kinetics, reflected by the need for a large overpotential to obtain a reaction current sufficient for practical applications. The rational design of electrocatalysts that accelerate OER kinetics has been a core activity in OER research in recent years. Most active OER electrocatalysts are based on precious-metal oxides such as $\mathrm{RuO}_{2}$ and $\mathrm{IrO}_{2}$, despite their high cost [1]. However, their use in large-scale commercial applications is expensive and challenging because of the cost and stability problems. Catalysts based on low-cost, highly active, non-noble-transition metals are becoming attractive alternatives for use in OERs.

Amorphous materials based on transition-metal compounds are attractive non-noble-metal catalysts because of their specific chemical structures and high concentrations of unsaturat- ed sites. Amorphous metal-based catalysts have performed well in OERs; for example, amorphous cobalt phosphate showed high activity in neutral water [2]. The OER activities of amorphous transition-metal oxides are superior to those of their crystalline counterparts. Because of their unusual amorphous structures, the OER catalytic properties of the amorphous mixed metal oxides $\mathrm{Fe}_{100-x-y} \mathrm{Co}_{y} \mathrm{Ni}_{z} \mathrm{O}_{x}$ are comparable to those of certain noble-metal catalysts, and are promising alternative amorphous electrocatalysts to noble-metal catalysts [3]. Furthermore, the surfaces of some crystalline catalysts can be transformed into an amorphous state, resulting in greatly improved OER activities. This was observed for a perovskite catalyst $\left(\mathrm{Ba}_{0.5} \mathrm{Sr}_{0.5} \mathrm{Co}_{0.8} \mathrm{Fe}_{0.2} \mathrm{O}_{3-\delta}\right)$ in the OER reaction; the results showed that the activity was related to the amorphous surfaces [4].

As well as amorphous metal compounds, amorphous alloys have shown great potential for use in catalytic hydrogenation [5-8] and battery materials [9,10]. Amorphous materials have

\footnotetext{
* Corresponding author. Tel: +61-2-93857355; E-mail: da-wei.wang@unsw.edu.au

This work was supported by the Australian Research Council Discovery Project (DP110100550).

DOI: 10.1016/S1872-2067(17)62811-0 | http://www.sciencedirect.com/science/journal/18722067 | Chin. J. Catal., Vol. 38, No. 6, June 2017
} 
high specific surface areas and amorphous alloys are easily synthesized, therefore their catalytic performance in the OER should be investigated. Transition metal-B alloys were first investigated as OER catalysts $[11,12]$. In the 1980s, the amorphous alloys $\mathrm{Fe}_{60} \mathrm{Co}_{20} \mathrm{Si}_{10} \mathrm{~B}_{10}$ and $\mathrm{Co}_{50} \mathrm{Ni}_{25} \mathrm{Si}_{15} \mathrm{~B}_{10}$ were identified as effective electrocatalysts for the OER $[13,14]$. These alloys were traditionally fabricated using a liquid quenching method, which limits the synthesis of nanostructured catalysts with high electrochemically active surface areas. The OER activities of metal-B alloys are affected by the synthesis temperature. Samples synthesized at medium temperatures are more active because the amorphous phase is converted to a crystalline phase at high temperatures. The industrial methods generally used for synthesizing transition metal-B alloys are (1) reduction of metal oxides using a mixture of boron carbide and carbon, (2) electrolysis, or (3) direct reaction of the elemental precursors [15].

Here, we report the OER performance and structural evolution of a nanostructured Co-B alloy wrapped by hydrotalcite nanosheets. The Co-B alloy was produced by chemically reducing transition-metal ions with $\mathrm{NaBH}_{4}$ [16]. Hydrotalcite nanosheets were formed synchronously during alloy formation by introducing a weak oxidizing agent. The microstructures and compositions of the Co-B alloy were determined and correlated with the electrochemical OER performance. The results show that wrapping in hydrotalcite nanosheets improved the activity of a slightly oxidized Co-B alloy; its activity was superior to that of a commercially available $\mathrm{Ir} / \mathrm{C}$ catalyst. The structural evolution during the OER was investigated using X-ray absorption spectroscopy (XAS) and X-ray photoelectron spectroscopy (XPS).

\section{Experimental}

\subsection{Materials}

$\mathrm{CoCl}_{2} \cdot 6 \mathrm{H}_{2} \mathrm{O}, \mathrm{Co}(\mathrm{Ac})_{2} \cdot 4 \mathrm{H}_{2} \mathrm{O}, \mathrm{NaBH}_{4}, \mathrm{NaOH}, \mathrm{Na}_{2} \mathrm{CO}_{3}$, and ethylene glycol were purchased from Sigma-Aldrich and used as received. All solutions were prepared using deionized water.

\subsection{Synthesis}

\subsubsection{Synthesis of $\mathrm{Co}-\mathrm{B}$}

In a typical Co-B synthesis, $\mathrm{NaBH}_{4}$ solution $(2 \mathrm{~mol} / \mathrm{L}, 25$ $\mathrm{mL}$ ) was added dropwise to a $\mathrm{CoCl}_{2}$ solution ( $\left.0.4 \mathrm{~mol} / \mathrm{L}, 25 \mathrm{~mL}\right)$ under stirring in a nitrogen atmosphere. Before mixing, nitrogen was bubbled through both solutions for $30 \mathrm{~min}$. The precipitated black powder was separated by filtration, washed thoroughly with water, and dried overnight in a vacuum oven at $70{ }^{\circ} \mathrm{C}$

\subsubsection{Synthesis of $\mathrm{Co}-\mathrm{B}-\mathrm{O}$}

In a typical Co-B-O synthesis, $25 \mathrm{~mL}$ of an aqueous solution of $\mathrm{NaBH}_{4}(2 \mathrm{~mol} / \mathrm{L})$ and $\mathrm{NaOH}(0.2 \mathrm{~mol} / \mathrm{L})$ were added dropwise to a $\mathrm{CoCl}_{2}$ solution $(0.4 \mathrm{~mol} / \mathrm{L}, 25 \mathrm{~mL})$ in air. The precipitated black powder was removed by filtration, washed thoroughly with water, and dried overnight in a vacuum oven at $70^{\circ} \mathrm{C}$.

\subsubsection{Synthesis of $\mathrm{Co}-\mathrm{O}$}

In a typical $\mathrm{Co}-\mathrm{O}$ synthesis, an aqueous solution of $\mathrm{NaOH}$ (0.2 mol/L, $25 \mathrm{~mL})$ was added dropwise to a $\mathrm{CoCl}_{2}$ solution $(0.4$ $\mathrm{mol} / \mathrm{L}, 25 \mathrm{~mL}$ ) in air. The precipitated green powder was removed by filtration, washed thoroughly with water, and dried overnight in a vacuum oven at $70{ }^{\circ} \mathrm{C}$. For comparison, $\mathrm{Co}_{3} \mathrm{O}_{4}$ was prepared using a previously reported method [17].

\subsection{Characterization}

The crystal structures of the samples were determined using powder X-ray diffraction (XRD; Bruker D8). XAS was performed using BL16A at the Taiwan National Synchrotron Radiation Research Center. Co K-edge X-ray absorption near-edge structure (XANES) spectroscopy was performed in fluorescence mode using a Lytle detector. The powder samples were adhered to Kapton tape. The incident beam was positioned at $45^{\circ}$ to the sample. The spectra were normalized using Athena software. Transmission electron microscopy (TEM) and selected area electron diffraction (SAED) analysis were performed using a FEI F20 transmission electron microscope. The samples for TEM and SAED were prepared by dispersing Co-B in ethanol. XPS was performed using a Kratos Axis ULTRA $\mathrm{X}$-ray photoelectron spectrometer. The incident radiation was monochromatic Al $K \alpha$ X-rays. The binding energies reported here were corrected using C $1 s(284.8 \mathrm{eV})$ from the carbon contamination layer. Raman spectra were obtained using an Invia Renishaw Raman spectrometer. The excitation source was a 532-nm green laser.

\subsection{Electrochemical measurements}

Electrochemical measurements were performed using a CHI 900C workstation. For these measurements, a catalyst sample (3 $\mathrm{mg}$ ) was dispersed in saturated chitosan solution ( $3 \mathrm{~mL}$ ) by sonication for $30 \mathrm{~min}$ to form a homogeneous ink. For linear sweep voltammetry (LSV) and cyclic voltammetry (CV), the catalyst ink $(12 \mu \mathrm{L})$ was cast onto the disc (radius $2 \mathrm{~mm}$ ) of a rotating ring-disc electrode. LSV was performed at $10 \mathrm{mV} / \mathrm{s}$ with the working electrode continuously rotating at 1600 $\mathrm{r} / \mathrm{min}$. CV was performed at a scanning rate of $30 \mathrm{mV} / \mathrm{s}$. Chronopotentiometry was used to study the structural evolution of the catalyst during the OER. The chronopotentiometric tests were performed at a constant current density of $10 \mathrm{~A} / \mathrm{g}$ using the catalyst ink $(60 \mu \mathrm{L})$ cast onto a carbon paste. All tests were performed in $0.1 \mathrm{~mol} / \mathrm{L} \mathrm{KOH}$ solution. A platinum wire was used as the counter electrode and $\mathrm{Hg} / \mathrm{HgO}$ was used as the reference electrode.

\section{Results and discussion}

The Co-B sample was synthesized by reducing $\mathrm{CoCl}_{2}$ with $\mathrm{NaBH}_{4}$ solution under nitrogen protection. Fig. 1(a) shows the XRD pattern of Co-B; the hump at $53.6^{\circ}$ is assigned to an amorphous Co-B alloy. The XANES results for $\mathrm{Co}-\mathrm{B}$ are shown in Fig. 1(b). The spectrum of the Co-B sample has a prominent shoulder at $7713 \mathrm{eV}$, which corresponds to Co metal and indi- 

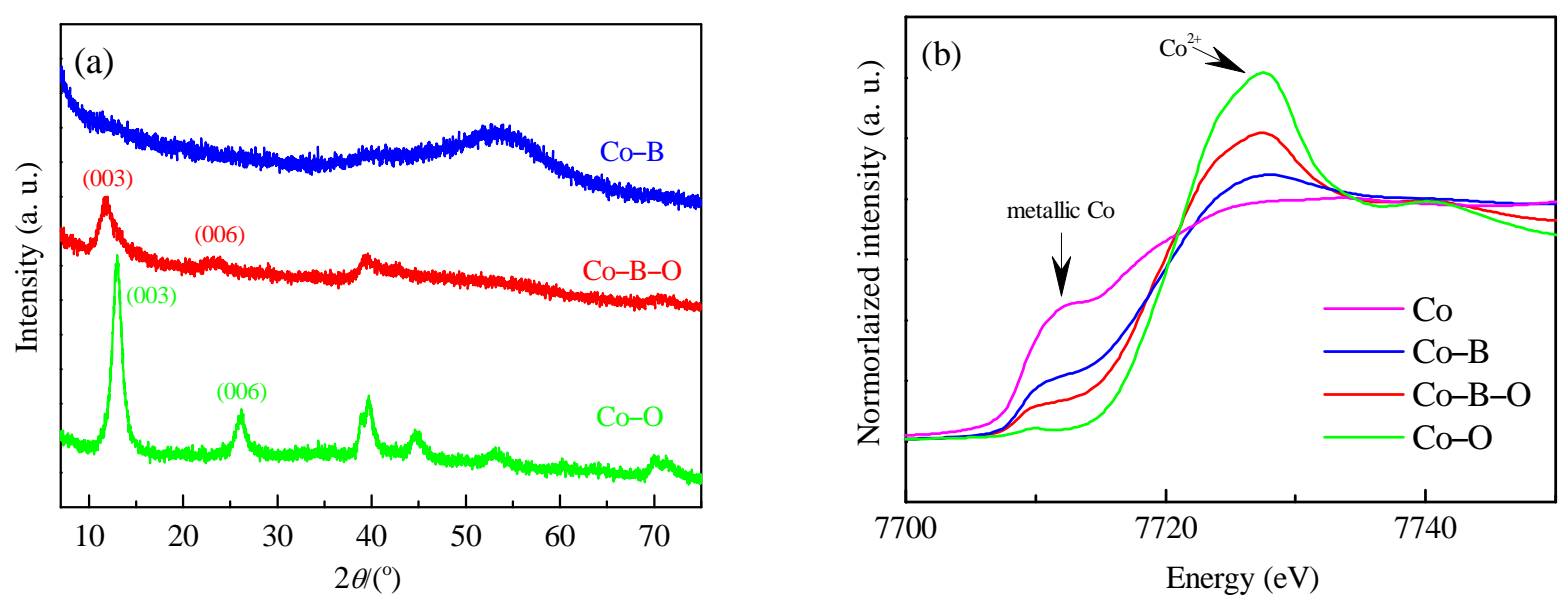

Fig. 1. XRD patterns (a) and XANES (b) results for $\mathrm{Co}-\mathrm{B}, \mathrm{Co}-\mathrm{B}-\mathrm{O}$, and $\mathrm{Co}-\mathrm{O}$.

cates the presence of metallic Co in Co-B. The weak peak at $7727.4 \mathrm{eV}$ is related to $\mathrm{Co}^{2+}$, which may arise from the partial oxidation of cobalt borides on exposure to air [18], and/or cobalt borate formed as a by-product during synthesis $[6,19,20]$.

A Co-B-O sample was produced using air and $\mathrm{NaOH}$ as oxidizing agents. The peaks in the XRD pattern of Co-B-O (Fig. 1(a)) are assigned to $\alpha-\mathrm{Co}(\mathrm{OH})_{2}$ with a large interlayer distance of $0.88 \mathrm{~nm}$. The broadness of the peaks shows that the $\alpha-\mathrm{Co}(\mathrm{OH})_{2}$ crystallinity is poor. A hump related to the amorphous Co-B alloy is observed at $53.6^{\circ}$. The XANES spectrum of Co-B-O (Fig. 1(b)) shows a shoulder at $7713 \mathrm{eV}$ and a peak at $7727.2 \mathrm{eV}$. The shoulder is related to metallic Co, which is con- sistent with the hump in the XRD pattern. The peak at 7727.2 $\mathrm{eV}$ is assigned to $\mathrm{Co}^{2+}$, which is associated with the $\alpha-\mathrm{Co}(\mathrm{OH})_{2}$ phase, as shown by the XRD pattern. The $\mathrm{Co}^{2+}$ peak is more prominent than the corresponding peak for the Co-B sample, suggesting the presence of $\alpha-\mathrm{Co}(\mathrm{OH})_{2}$ in Co-B-O. The XRD and XANES results both suggest that $\mathrm{Co}-\mathrm{B}-\mathrm{O}$ is a mixture of $\mathrm{Co}-\mathrm{B}$ and $\alpha-\mathrm{Co}(\mathrm{OH})_{2}$. As a control, $\alpha-\mathrm{Co}(\mathrm{OH})_{2}$, denoted by $\mathrm{Co}-\mathrm{O}$, was synthesized using the same procedure as for Co-B-O, but without adding $\mathrm{NaBH}_{4}$. Its XRD pattern in Fig. 1(a) shows a hydrotalcite-like layered structure with an interlayer distance of $0.79 \mathrm{~nm}$. The XANES spectrum of Co-O in Fig. 1(b) shows a strong peak at $7727.4 \mathrm{eV}$, which is assigned to $\mathrm{Co}^{2+}$.

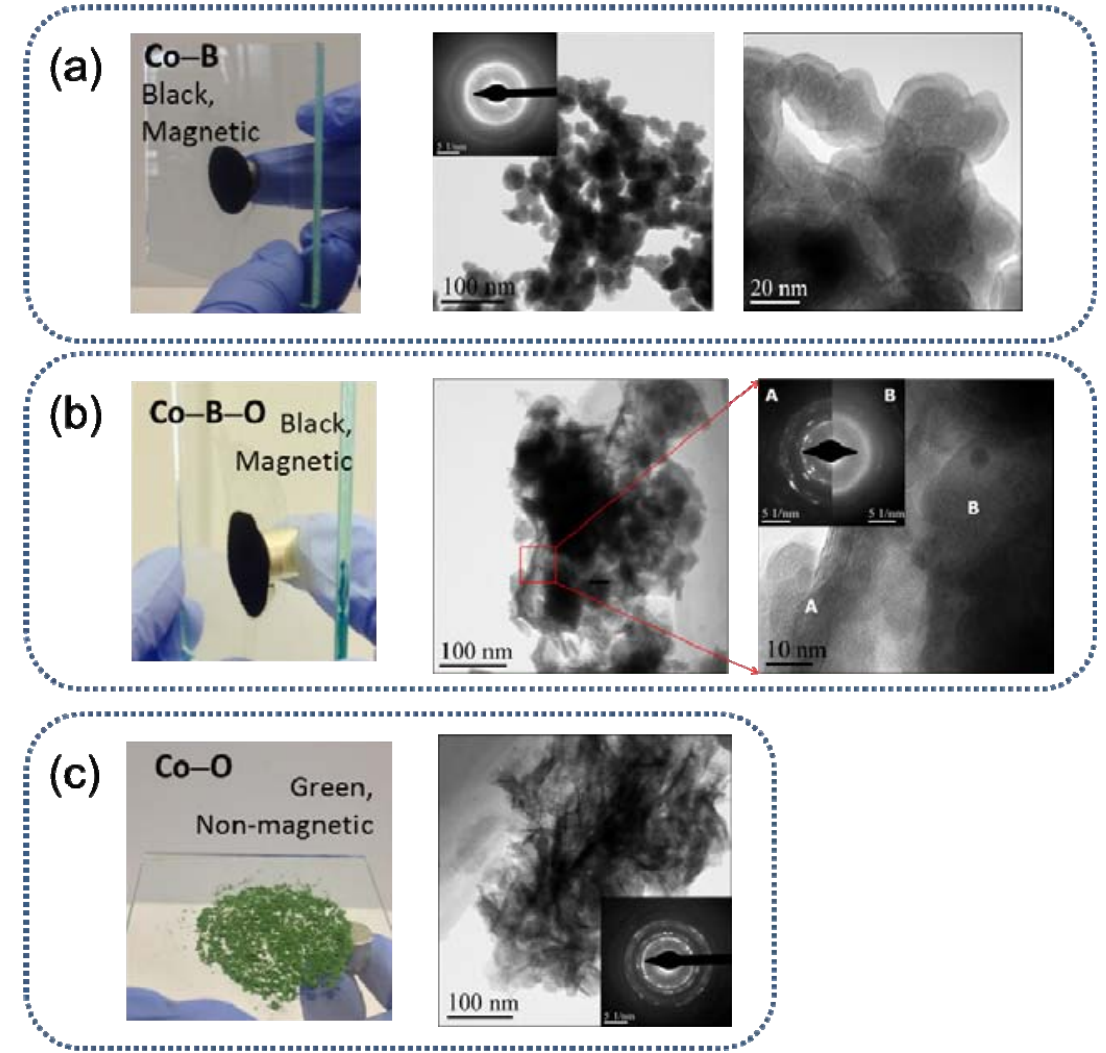

Fig. 2. TEM images and photographs of Co-B (a), Co-B-O (b), and Co-O (c). Insets show corresponding SAED patterns. 
The photographs of the $\mathrm{Co}-\mathrm{B}, \mathrm{Co}-\mathrm{B}-\mathrm{O}$, and $\mathrm{Co}-\mathrm{O}$ samples in Fig. 2 show that they differ in colour and that the Co-B alloys are magnetic. TEM images showing the morphologies of the samples are also shown in Fig. 2. Co-B consists of aggregated globular particles of size 25-50 nm (Fig. 2(a)). These particles have shells of thickness $\sim 5 \mathrm{~nm}$ (Fig. 2(b)). According to the literature, the shells may consist of amorphous oxides of $B$ and Co, and a cobalt borate phase formed as a by-product during synthesis $[6,19,20]$. This layer differs from the hydrotalcite nanosheets and has a limited effect on the OER performance. The SAED pattern in the inset shows a diffuse ring corresponding to the amorphous structure. Co-B-O consists of 2-50 nm nanoparticles wrapped by thin sheets (Fig. 2(b)). The area indicated by $A$ in Fig. $2 b$ shows lattice fringes similar to those of Co-O (Fig. 2(c)). The corresponding SAED (left half of the inset) is also similar to that of $\mathrm{Co}-\mathrm{O}$, and is assigned to $\alpha-\mathrm{Co}(\mathrm{OH})_{2}$ based on the XRD results (Fig. 1). However, there are no lattice fringes in area $\mathrm{B}$, and the SAED of this area (right half of the inset) shows a diffused disc that is related to an amorphous structure in the Co-B alloy. Fig. 2(c) shows that Co-O consists of thin sheets, which is the typical hydrotalcite morphology. The SAED pattern also indicates that the Co-O sample is crystalline. These results show that Co-B is mainly amorphous and dominated by the Co-B alloy phase, whereas $\mathrm{Co}-\mathrm{B}-\mathrm{O}$ is a composite consisting of an amorphous alloy wrapped by hydrotalcite nanosheets. The surface compositions of Co-B and Co-B-O were further investigated using XPS. The XPS survey spectra in Fig. 3(a) confirm the presence of oxygen on the surfaces of $\mathrm{Co}-\mathrm{B}$ and $\mathrm{Co}-\mathrm{B}-\mathrm{O}$. The high-resolution $\mathrm{B} 1 s$ and Co $2 p$ XPS spectra in Fig. 3(b) and (c) show the co-existence of cobalt borides, and oxides of Co and B in Co-B. However, cobalt borides were not detected in $\mathrm{Co}-\mathrm{B}-\mathrm{O}$, indicating that the cobalt borides might have reacted with $\mathrm{NaOH}$ to form the hydrotalcite phase.

The OER electrocatalytic activities of the three samples were investigated using voltammetry techniques; the results are shown in Fig. 4. The cyclic voltammogram of Co-B has two primary features: an anodic peak in the potential region $1.15-1.35 \mathrm{~V}$ vs the reversible hydrogen electrode (RHE) and an anodic shoulder emerging from $1.55 \mathrm{~V}$, characteristic of the OER process. The first anodic peak corresponds to oxidation of $\mathrm{Co}^{2+}$ to $\mathrm{Co}^{3+}$. Despite the large amount of metallic Co in Co-B, no oxidation peak related to the transformation of metallic Co to $\mathrm{Co}^{2+}$ is observed because this transformation occurs at $0.1-0.3$ $\mathrm{V}$ vs the RHE [21]. This suggests that the oxidation current is mainly derived from the exterior cobalt borides in the amorphous shell covering the alloy nanoparticles. The sharp increase in the oxidation current from $1.55 \mathrm{~V}$ is attributed to the OER. The Co-B OER overpotential at $10 \mathrm{~mA} / \mathrm{cm}^{2}$ is smaller than that for $\mathrm{Co}_{3} \mathrm{O}_{4}$ (Fig. 4(b)). At $1.7 \mathrm{~V}$, the OER current density for Co-B $\left(6.6 \mathrm{~mA} / \mathrm{cm}^{2}\right)$ is almost an order of magnitude larger than that for $\mathrm{Co}_{3} \mathrm{O}_{4}\left(0.85 \mathrm{~mA} / \mathrm{cm}^{2}\right)$. Co-B therefore shows considerable electrocatalytic activity in the OER. The CV profiles for Co-B-O and Co-O are similar: both have an anodic peak for the oxidation of hydrotalcite at a potential lower than that for Co-B oxidation. Nevertheless, the anodic current for the oxidation of $\mathrm{Co}^{2+}$ to $\mathrm{Co}^{3+}$ on $\mathrm{Co}-\mathrm{B}-\mathrm{O}$ is much larger than that on $\mathrm{Co}-\mathrm{O}$.

The linear sweep voltammogram of Co-B-O (Fig. 3(b)) also shows an anodic peak related to the oxidation of $\mathrm{Co}^{2+}$ to $\mathrm{Co}^{3+}$ in the potential region $1.15-1.25 \mathrm{~V}$ and an oxidation current attributable to the OER, which starts to increase at $1.52 \mathrm{~V}$. The OER overpotential of Co-B-O is lower than that of $\mathrm{Co}-\mathrm{B}$ at 10 $\mathrm{mA} / \mathrm{cm}^{2}$. The OER current density at $1.7 \mathrm{~V}$ for Co-B-O is 14.3 $\mathrm{mA} / \mathrm{cm}^{2}$, more than two-fold greater than that for Co-B. The OER activity of Co-B-O is therefore significantly better than that of Co-B. The OER current density of Co-B-O is even higher than that of the commercially available precious-metal catalyst $\mathrm{Ir} / \mathrm{C}\left(9.4 \mathrm{~mA} / \mathrm{cm}^{2}\right.$ at $\left.1.7 \mathrm{~V}\right)$. This improvement is related to the novel structure of $\mathrm{Co}-\mathrm{B}-\mathrm{O}$, i.e., an $\alpha-\mathrm{Co}(\mathrm{OH})_{2}$-wrapped Co-B alloy. The effects of $\alpha-\mathrm{Co}(\mathrm{OH})_{2}$ were investigated by performing LSV on Co-O under the same conditions as for Co-B-O; the results are shown in Fig. 4(b). The OER current for Co-O starts to increase at $1.55 \mathrm{~V}$ and reaches $7.2 \mathrm{~mA} / \mathrm{cm}^{2}$ at $1.7 \mathrm{~V}$. Its activity is slightly higher than that of $\mathrm{Co}-\mathrm{B}$, but lower than that of Ir/C. The OER activity of Co-B-O is therefore not simply the sum of the activities of Co-B and $\alpha-\mathrm{Co}(\mathrm{OH})_{2}$. Phase junctions can significantly improve catalytic activities $[22,23]$. We postulate that the superior OER activity of $\mathrm{Co}-\mathrm{B}-\mathrm{O}$ is related to phase junctions between the Co-B alloy and $\alpha-\mathrm{Co}(\mathrm{OH})_{2}$, inducing a synergistic effect.

Chronopotentiometry was performed to determine the stabilities of Co-B and Co-B-O during the OER, and compare them with that of Ir/C (Fig. 4(c)). At a current density of $10 \mathrm{~A} / \mathrm{g}$, the Co-B potential increased from 1.6 to $1.76 \mathrm{~V}$ during a 12 -h test,
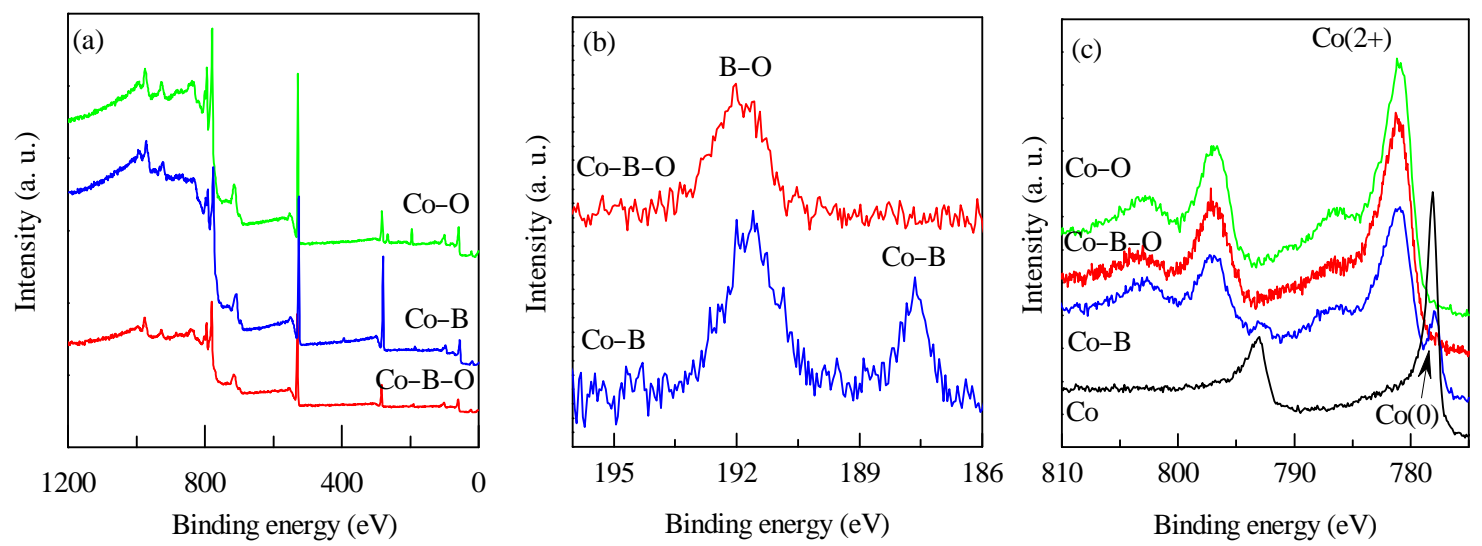

Fig. 3. XPS spectra of Co-B, Co-B-O, and Co-O. (a) Survey; (b) B 1s; (c) Co $2 p$. 

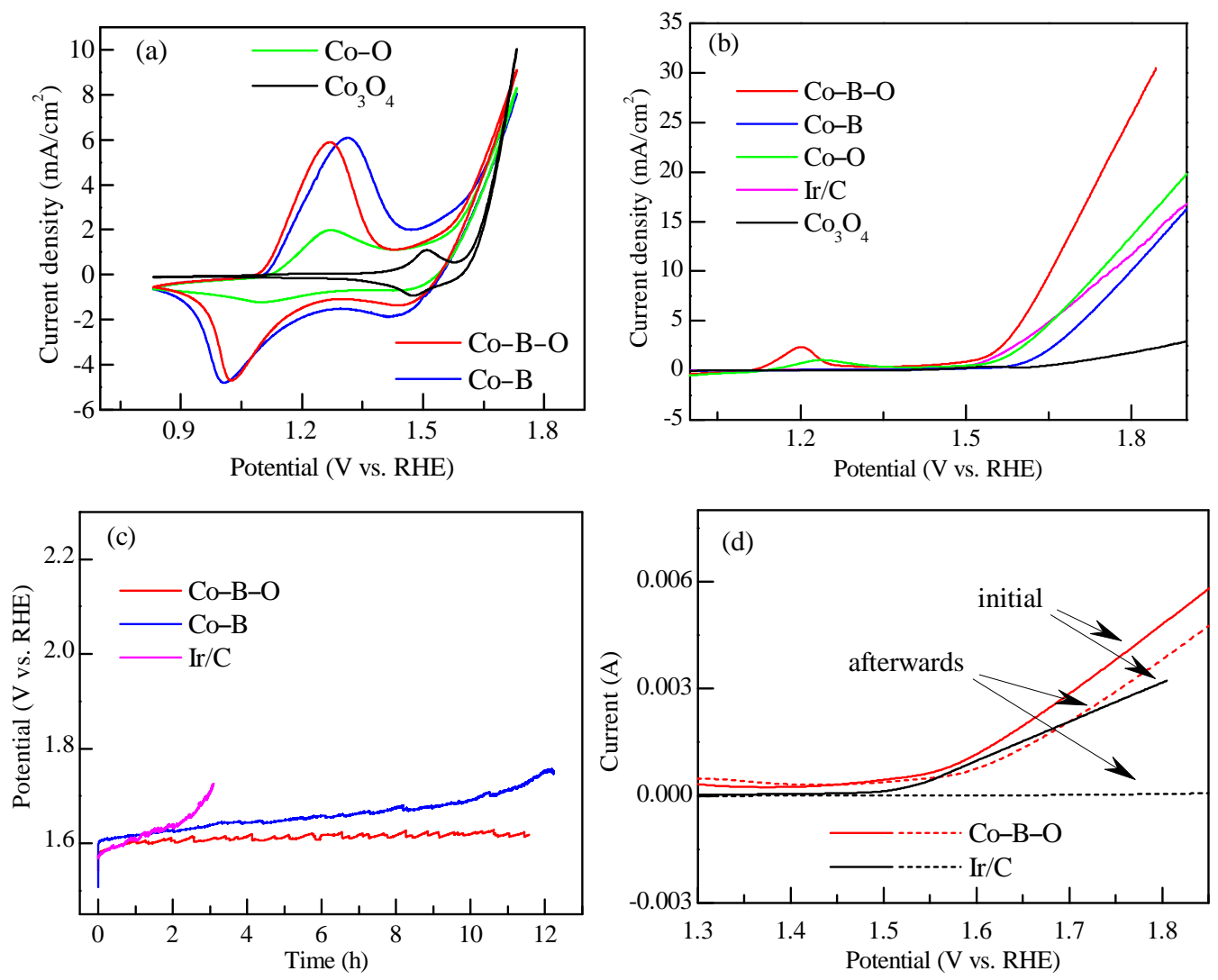

Fig. 4. Cyclic voltammograms (a) and linear sweep voltammograms (b) of Co-B, Co-B-O, Co-O, and $\mathrm{Co}_{3} \mathrm{O}_{4}$, and the current density was calculated based on geometric area of electrode disc; (c) Chronopotentiometric results at constant current density of $10 \mathrm{~A} / \mathrm{g}$; (d) Linear sweep voltammograms of $\mathrm{Co}-\mathrm{B}-\mathrm{O}$ and $\mathrm{Ir} / \mathrm{C}$ electrodes after chronopotentiometric tests.

indicating low stability. In contrast, only a slight potential increase of $20 \mathrm{mV}$, from 1.58 to $1.6 \mathrm{~V}$, was observed during the chronopotentiometric testing of $\mathrm{Co}-\mathrm{B}-\mathrm{O}$ under the same conditions, indicating excellent stability. In contrast, the Ir/C catalyst started to lose activity within $2 \mathrm{~h}$, as shown by fast polarization. The LSV curves before and after the chronopotentiometric tests are shown in Fig. 4(d). The Co-B-O activity was still good after the stability test, whereas $\mathrm{Ir} / \mathrm{C}$ was virtually inactive in the OER.

The structural changes in Co-B-O after the OER were clari-

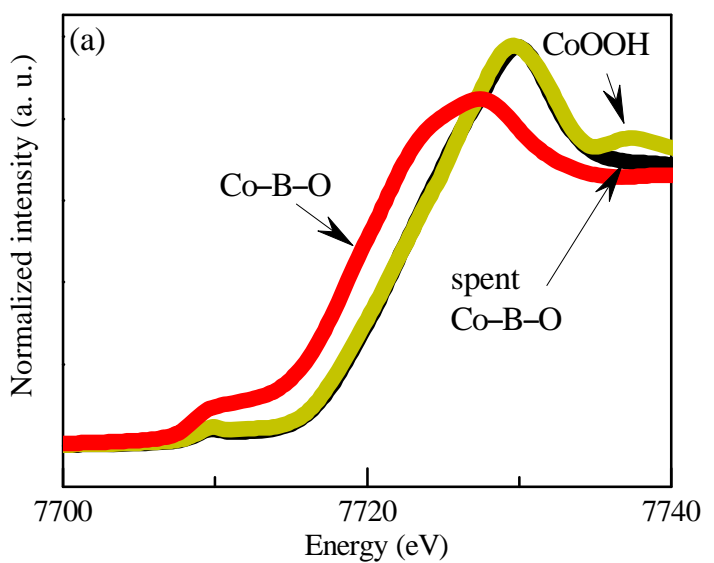

fied using a combination of XANES and XPS. The XANES spectrum of Co-B-O after the OER (Fig. 5(a)) shows that compared with that of the as-prepared $\mathrm{Co}-\mathrm{B}-\mathrm{O}$, the shoulder assigned to metallic Co shifts to lower energy and the absorption edge shifts to a position close to that for $\mathrm{CoOOH}$, implying that $\alpha-\mathrm{Co}(\mathrm{OH})_{2}$ present in $\mathrm{Co}-\mathrm{B}-\mathrm{O}$ is oxidized to $\mathrm{Co}^{3+}$-containing species during oxidation. The high-resolution Co $2 p$ XPS spectrum in Fig. 5(b) confirms that $\mathrm{Co}^{2+}$ on the surface of $\mathrm{Co}-\mathrm{B}-\mathrm{O}$ was oxidized to $\mathrm{Co}^{3+}$ during the OER. Fig. 6 shows that the Raman spectrum of the spent Co-B-O is similar to that of

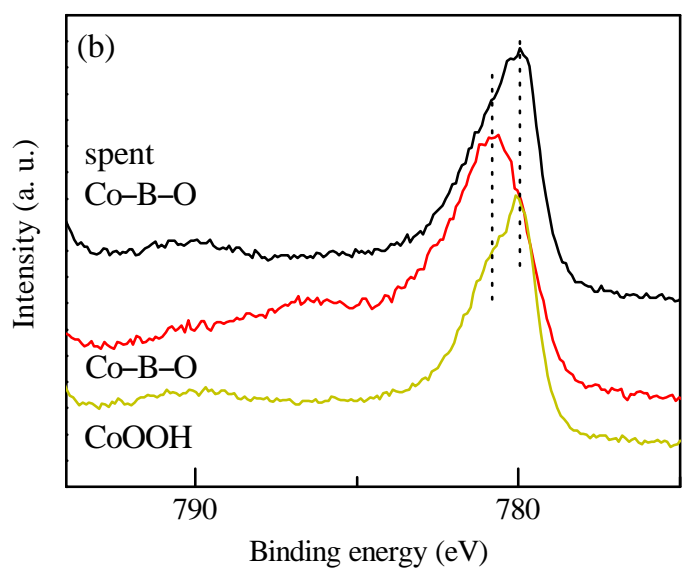

Fig. 5. XANES (a) and XPS (b) results for Co-B-O after chronopotentiometric testing for $12 \mathrm{~h}$. 


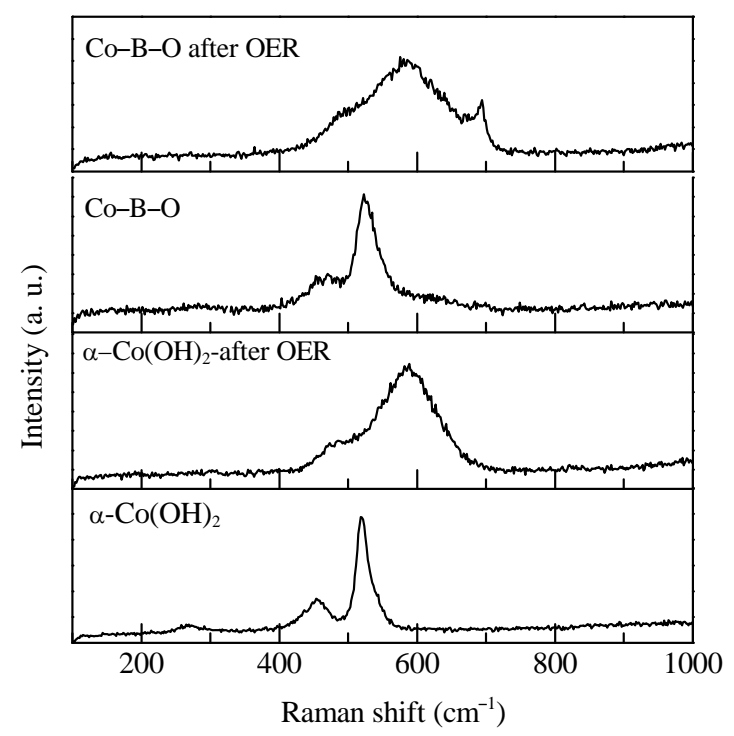

Fig. 6. Raman spectra of $\mathrm{Co}-\mathrm{B}-\mathrm{O}$ and $\alpha-\mathrm{Co}(\mathrm{OH})_{2}$ before and after chronopotentiometric testing for $12 \mathrm{~h}$.

$\alpha-\mathrm{Co}(\mathrm{OH})_{2}$ after the OER, implying that Co-B-O is transformed to amorphous (hydrous) cobalt oxides during the OER; this amorphous phase probably contributes to the superior OER activity and stability of Co-B-O.

\section{Conclusions}

Amorphous Co alloy-based catalysts are promising candidates for OER electrocatalysts. A novel catalyst consisting of a Co-B alloy wrapped by $\alpha-\mathrm{Co}(\mathrm{OH})_{2}$ showed greatly improved OER activity and stability, even higher than those of the commercially available precious-metal catalyst $\mathrm{Ir} / \mathrm{C}$. At a potential of $1.7 \mathrm{~V}$, the OER current density of the hydrotalcite-wrapped alloy was $14.3 \mathrm{~mA} / \mathrm{cm}^{2}$, compared with $9.4 \mathrm{~mA} / \mathrm{cm}^{2}$ for the $\mathrm{Ir} / \mathrm{C}$ catalyst. XANES and XPS analyses both showed that the Co atoms on the surface of the composite catalyst were oxidized to $\mathrm{Co}^{3+}$, i.e., a chemical coordination environment similar to that of cobalt oxyhydroxide.

\section{Acknowledgment}

The authors acknowledge the facilities, and the scientific and technical assistance of the Australian Microscopy \& Microanalysis Research Facility at the Centre for Microscopy and Microanalysis, The University of Queensland.

\section{References}

[1] Y. Lee, J. Suntivich, K. J. May, E. E. Perry, Y. Shao-Horn, J. Phys. Chem. Lett., 2012, 3, 399-404.

[2] M. W. Kanan, D. G. Nocera, Science, 2008, 321, 1072-1075.

[3] R. D. L. Smith, M. S. Prévot, R. D. Fagan, Z. P. Zhang, P. A. Sedach, M. K. J. Siu, S. Trudel, C. P. Berlinguette, Science, 2013, 340, 60-63.

[4] K. J. May, C. E. Carlton, K. A. Stoerzinger, M. Risch, J. Suntivich, Y. L. Lee, A. Grimaud, Y. Shao-Horn, J. Phys. Chem. Lett., 2012, 3, 3264-3270.

[5] H. X. Li, X. F. Chen, M. H. Wang, Y. P. Xu, Appl. Catal. A, 2002, 225, 117-130.

[6] A. Garron, D. Świerczyński, S. Bennici, A. Auroux, Int. J. Hydrogen Energy, 2009, 34, 1185-1199.

[7] C. Wu, Y. Bai, F. Wu, B. L. Yi, H. M. Zhang, Int. J. Hydrogen Energy, 2010, 35, 2675-2679.

[8] C. Wu, F. Wu, Y. Bai, B. L. Yi, H. M. Zhang, Mater. Lett., 2005, 59, 1748-1751.

[9] Y. D. Wang, X. P. Ai, Y. L. Cao, H. X. Yang, Electrochem. Commun., 2004, 6, 780-784.

[10] X. P. Gao, H. X. Yang, Energy Environ. Sci., 2010, 3, 174-189.

[11] T. Osaka, H. Ishibashi, T. Endo, T. Yoshida, Electrochim. Acta, 1981, 26, 339-343.

[12] T. Osaka, Y. Iwase, H. Kitayama, T. Ichino, Bull. Chem. Soc. Jpn., 1983, 56, 2106-2111.

[13] G. Kreysa, B. Håkansson, J. Electroanal. Chem. Interfacial Electrochem., 1986, 201, 61-83.

\section{Graphical Abstract}

\section{Chin. J. Catal., 2017, 38: 1021-1027 doi: 10.1016/S1872-2067(17)62811-0}

\section{Hydrotalcite-wrapped Co-B alloy with enhanced oxygen evolution activity}

Xue Leng, Kuang-Hsu Wu, Bing-Jian Su, Ling-Yun Jang, Ian R. Gentle, Da-Wei Wang *

The University of Queensland, Australia; University of New South Wales, Australia; National Synchrotron Radiation Research Center, China

A combination of amorphous particles and layered sheets can improve water oxidation reactions for clean energy sources.

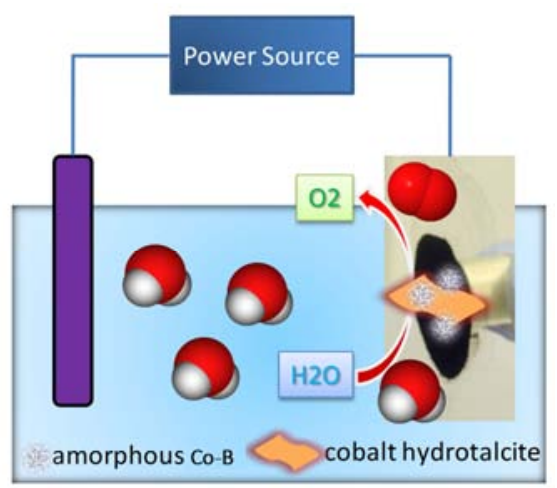


[14] H. Alemu, K. Jüttner, Electrochim. Acta, 1988, 33, 1101-1109.

[15] B. Ganem, J. O. Osby, Chem. Rev., 1986, 86, 763-780.

[16] H. I. Schlesinger, H. C. Brown, A. E. Finholt, J. R. Gilbreath, H. R. Hoekstra, E. K. Hyde, J. Am. Chem. Soc., 1953, 75, 215-219.

[17] X. W. Xie, Y. Li, Z. Q. Liu, M. Haruta, W. J. Shen, Nature, 2009, 458, 746-749.

[18] D. K. Aswal, K. P. Muthe, A. Singh, S. Sen, K. Shah, L. C. Gupta, S. K. Gupta, V. C. Sahni, Phys. C, 2001, 363, 208-214.

[19] A. M. Ozerova, V. I. Simagina, O. V. Komova, O. V. Netskina, G. V. Odegova, O. A. Bulavchenko, N. A. Rudina, J. Alloy. Compd., 2012,
513, 266-272.

[20] A. Corrias, G. Ennas, G. Licheri, G. Marongiu, G. Paschina, Chem. Mater., 1990, 2, 363-366.

[21] M. E. G. Lyons, M. P. Brandon, Int. J. Electrochem. Sci., 2008, 3, 1425-1462.

[22] T. Kawahara, Y. Konishi, H. Tada, N. Tohge, J. Nishii, S. Ito, Angew. Chem. Int. Ed., 2002, 41, 2811-2813.

[23] J. Zhang, Q. Xu, Z. C. Feng, M. J. Li, C. Li, Angew. Chem. Int. Ed., 2008, $47,1766-1769$.

\section{层状水滑石结构包覆钴硼合金的电化学产氧性能 \\ 冷 雪 ${ }^{\mathrm{a}}$, 吴光栩 ${ }^{\mathrm{a}}$, 苏并坚 ${ }^{\mathrm{c}}$, 张凌云 ${ }^{\mathrm{c}}$, Ian R. Gentle ${ }^{\mathrm{b}}$, 王大伟 ${ }^{\mathrm{a}, \mathrm{b},{ }^{*}}$ \\ a昆士兰大学化学与分子生命科学系, 布里斯班4072, 澳大利亚 \\ 新南威尔士大学化学工程系, 悉尼2052, 澳大利亚 \\ c国立同步辐射研究中心研究部, 台湾新竹 300 , 中国}

摘要: 电解水制氧是一种非常有吸引力的转化储存间歇式能源的技术. 本文着重研究了非晶态钴嗍合金的电解水产氧性 能. 非晶态钴硼合金可以通过磀氢化钠直接还原钴盐来获取, 并表现出较高的电化学活性. 对钴嗍合金的弱氧化, 产生了 类水滑石结构的钴氢氧化物, 可进一步提高该类催化剂的整体催化活性, 达到接近商业催化剂水平.

关键词: 非晶态合金; 产氧反应; 电催化剂

收稿日期: 2017-02-08. 接受日期: 2017-03-04. 出版日期: 2017-06-05.

*通讯联系人. 电话: +61-2-93857355; 电子信箱: da-wei.wang@unsw.edu.au

基金来源：澳大利亚研究理事会(DP110100550).

本文的英文电子版由Elsevier出版社在ScienceDirect上出版(http://www.sciencedirect.com/science/journal/18722067). 